\title{
TESTAMENTOS, OBRAS PIADOSAS Y CONFLICTOS: MONTEVIDEO ENTRE FINALES DEL SIGLO XVIII Y COMIENZOS DEL XIX
}

\author{
POR \\ WiLSON F. GONZÁLEZ DEMURo \\ Facultad de Humanidades y Ciencias de la Educación, Departamento de Historia Americana. \\ Universidad de la República (Montevideo)
}

\begin{abstract}
RESUMEN
Hasta mediados del siglo XIX algunos habitantes de Montevideo prescribían por vía testamentaria la fundación de obras piadosas, como capellanías. Esto generaba en ocasiones serios problemas legales, uniendo intereses económicos y espirituales de los descendientes, generando singulares conflictos entre ellos. El seguimiento de dos casos concretos permite arrojar más luz sobre el proceso de creciente complejización de las relaciones sociales en las etapas finales de la época colonial rioplatense.
\end{abstract}

PALABRAS CLAVE: Montevideo, época colonial, testamentos, capellanías, conflictos.

\section{«TESTAMENTS, PIOUS WORKS AND CONFLICTS: MONTEVIDEO BETWEEN LATE XVIII AND EARLY XIX CENTURIES»}

\begin{abstract}
Until the middle of XIX century some inhabitants of Montevideo prescribed by testaments the foundation of pious works, like chaplaincies. Sometimes, this originated serious legal problems, confronting economic and spiritual interests of the descendants, and generating special conflicts among them. The analysis of two particular cases allows us to enlighten the process of increasing complexity of social relationships at the end of the colonial epoch in the River Plate.
\end{abstract}

KEY WORDS: Montevideo, colonial period, last wills, chaplaincies, conflicts.

Recibido/Received 04-08-2009

Aceptado/Accepted 07-06-2010 
El presente trabajo ${ }^{1}$ es una aproximación a la «cuestión familiar» en Montevideo a finales de la época colonial hispánica desde una perspectiva socioeconómica que toma en cuenta particularmente en tres elementos: los mecanismos sucesorios, el patrimonio familiar y las carreras sacerdotales, articulados en un contexto cultural específico, el del «régimen de cristiandad» dominante en el mundo hispanoamericano desde la conquista hasta por lo menos las tres primeras décadas del siglo XIX. ${ }^{2}$ Es en este marco que encuentran explicación satisfactoria determinadas actitudes individuales y colectivas puestas de manifiesto ante el fenómeno de la muerte y sus aspectos materiales y espirituales.

Como ya ocurriera anteriormente ${ }^{3}$ este artículo se origina en una investigación llevada a cabo por el autor junto a dos colegas de la Facultad de Humanidades y Ciencias de la Educación de la Universidad de la República (Montevideo), sobre rituales funerarios y prácticas devocionales durante el último tramo de la dominación hispánica (1790-1814). ${ }^{4}$ En esta oportunidad el análisis se extiende sobre algunos asuntos no tratados allí y sobre un período mayor, 1778 a 1841 .

ESPIRITUALIDAD Y MATERIALISMO EN LA DOCUMENTACIÓN TESTAMENTARIA. LAS FUNDACIONES PIADOSAS Y LOS BIENES HEREDITARIOS

El tema de la muerte y sus múltiples derivaciones ha generado una abundante bibliografía. Conocida es la importante influencia francesa al respecto, con varios estudios ya clásicos de Philippe Ariès, Michel Vovelle, Pierre Chaunu o Jacques Le Goff. En España el número de obras dedicadas a esta temática y sus peculiaridades regionales entre los siglos XVI y XIX se ha multiplicado en las últimas décadas, lo mismo que en América aunque en una escala menor.

En referencia al caso castellano, pero manejando categorías de validez más general, Máximo García Fernández delimita cuatro «vertientes de la muerte»:

\footnotetext{
${ }^{1}$ Agradezco a los evaluadores de Hispania Sacra, cuyos comentarios y sugerencias a una primera versión de este artículo me han ayudado a mejorarlo.

${ }^{2}$ Roberto DI STEFANO, «De la cristiandad colonial a la Iglesia nacional. Perspectivas de investigación en historia religiosa de los siglos XVIII y XIX», Andes, 11, Universidad Nacional de Salta (2000), pp. 84-87.

${ }^{3}$ Wilson GonZÁlez Demuro, «Iglesia y crisis monárquica en el Río de la Plata al finalizar la época colonial. Un caso: Montevideo y su cura vicario, Juan José Ortiz (1783-1815)», Anuario de Estudios Americanos, 62.1 (enero-junio 2005), pp. 161-180.

${ }^{4}$ Andrea Bentancor Bossio - Arturo Ariel Bentancur - Wilson González Demuro, Muerte y religiosidad en el Montevideo colonial. Una historia de temores y esperanzas, Montevideo, Ediciones de la Banda Oriental, 2008, 332 pp. Hago constar que el relevamiento de algunos documentos citados en el presente artículo fue hecho por el Dr. Arturo Bentancur en el curso de la citada investigación.
} 
a) la «salvífica», en la que las almas del testador y de parte de su famila se veían beneficiadas espiritualmente; b) la «sociofamiliar», cuando familiares y entidades tales como cofradías y organizaciones benéficas obtenían recursos materiales directos; c) la «testamentario-judicial», compuesta por los gastos de todo orden que el mismo acto de morir ocasionaba: médicos, escribanos, ceremonial de la sepultura, etc.; y por último, d) la «específicamente hereditaria», que involucraba bienes dotales, donaciones, pago de deudas, etc. ${ }^{5}$ Las fuentes que permiten avanzar en la exploración de estas vertientes son, básicamente, inventarios de bienes, tasaciones y sobre todo los testamentos.

Los documentos dieciochescos revelan con toda nitidez el nivel de imbricación a que llegaban lo espiritual y lo material, lo religioso y lo económico. Tanto quienes expedían su testamento como quienes se dedicaban a su redacción y fiscalización conocían esa complejidad. Philippe Ariès considera esta declaración de últimas voluntades como «el medio religioso y cuasi sacramental de ganar los aeterna sin perder por completo los temporalia, de asociar las riquezas a la obra de la salvación». Lo define como «un contrato de seguridad concluido entre el individuo mortal y Dios, por mediación de la Iglesia». ${ }^{6}$ La idea que sintetiza los objetivos de este documento es la de dar a cada uno lo suyo: «la hacienda a los herederos y el cuerpo a la tierra y el alma a Dios».

Para el tratadista Alexo Venegas, cuya obra se difundiera en los siglos XVI y XVII, el testamento era una «protestación de justicia con que el hombre se apareja a dar a cada uno lo suyo, cada cuando que el tiempo determinado por Dios fuere cumplido». ${ }^{7}$ Instrumento idóneo para quitar peso a la conciencia y prevenir disputas entre los deudos, también se lo ha entendido como «consuelo y último vale de los que mueren». ${ }^{8}$

A modo de resumen, los principales objetivos de todo buen testamento pueden enumerarse así: dar los bienes materiales a los herederos, lo adeudado a los acreedores, la limosna a los pobres, el cuerpo a la tierra y el alma a Dios. ${ }^{9}$

\footnotetext{
5 Máximo GARCÍA FERnÁndez, Herencia y patrimonio familiar en la Castilla del Antiguo Régimen (1650-1834). Efectos socioeconómicos de la muerte y la partición de bienes, Valladolid, Secretariado de Publicaciones de la Universidad de Valladolid, 1995, pp. 15-16.

${ }^{6}$ Philippe ARIÉs, El hombre ante la muerte, Madrid, Taurus, 1999, p.163; Soledad GómEZ NAVARRO, Una elaboración cultural de la experiencia del morir, Córdoba, Servicio de Publicaciones de la Universidad de Córdoba, 1998, p. 54.

${ }^{7}$ Alexo Venegas, Agonía del tránsito de la muerte con los avisos y consuelos que cerca de ella son provechosos [primera edición en Toledo, 1553], Santiago de Chile, Cruz del Sur, 1948, p. 37.

${ }^{8}$ María Isabel SeOAnE, Forma y contenido de los testamentos bonaerenses del siglo XVIII. Estudio inshistoriográfico, Buenos Aires, s/e, 1995, p. 8; Philippe ARIÉs, Morir en Occidente. Desde la Edad Media hasta nuestros días, Buenos Aires, Adriana Hidalgo Editora, 2000, p. 100.

${ }^{9}$ BentANCOR - BentANCUR - GonzÁlez, Muerte y religiosidad..., ob. cit., pág. 38; Francisco Javier LORENZO PINAR, Muerte y ritual en la Edad Moderna: el caso de Zamora (1500-1800), Salamanca, Universidad de Salamanca, 1991, p. 21; Gómez NAVARro, Una elaboración... ob. cit., p. 53.
} 
De modo que este documento, en España como en América, era pieza clave para la distribución de los bienes patrimoniales entre los herederos y la estipulación precisa de montos destinados a pagos de deudas y mandas piadosas de todo tipo. La herencia era además, junto con la dote, uno de los mecanismos más importantes en la transmisión de bienes al interior de la estructura familiar. La segunda solía ser nada más que un adelanto que al casarse la mujer recibía de su legítima, porción de bienes hereditarios que por derecho le correspondía. ${ }^{10}$ Las particiones de tales bienes constituían pues un elemento clave en la vida familiar en tanto la continuidad, consolidación o expansión del patrimonio y el futuro económico de cada uno de los afectados a la tramitación testamentaria se definían en esta instancia.

Con frecuencia aparecía explicitado entre las voluntades póstumas el deseo de fundar alguna obra piadosa: memorias de misas, aniversarios, donaciones a hospitales o capellanías.

Las capellanías formaban parte del conjunto de obras pías generalmente fundadas para beneficiar económicamente a un hijo, sobrino u otra persona del entorno familiar o externa al mismo que optara por la carrera eclesiástica. Suponían la existencia de tres actores principales: fundador, patrono y capellán. El primero, como acaba de señalarse, destinaba cierta suma de dinero o bienes inmuebles que constituían el capital de la fundación y se denominaba principal. Garantizaba antes que nada la manutención total o parcial de un clérigo, el capellán, que contaba de este modo con determinados ingresos fijos (la congrua sustentación) recibidos a cambio de celebrar misas por el alma del instituyente o de quienes él dispusiera, sin perjuicio de imponérsele otras cargas litúrgicas. El sacerdote quedaba sujeto a ciertas exigencias pero al mismo tiempo era beneficiario de la pía voluntad del fundador, quien también nombraba un administrador o patrono. Éste debía designar un cura que se encargara del servicio -si no lo había hecho el propio fundador con anterioridad- y asegurar su sostenimiento económico procurando que la inversión inicial mantuviera o aumentara su valor. ${ }^{11}$

Estas instituciones configuraban una especie de bien hereditario de singular perfil, espiritual y material a la vez. Como subrayara José Pedro Barrán, los fundadores obtenían beneficios para su alma en tanto las misas ordenadas y efectivamente celebradas contribuían a su salvación eterna, pero también para su prestigio personal y el de su familia. La espiritualización de determinados bienes no implicaba «su total desmaterialización ya que ellos seguían produciendo beneficios -materiales, de prestigio, etc.- en el más aquí al testador y su

${ }^{10}$ Véase el trabajo de Roxana BorXADós, «Transmisión de bienes en familias de elite: los mayorazgos en La Rioja colonial», Andes, 10, Universidad Nacional de Salta (1999), p. 51.

${ }^{11}$ BentanCor - BentANCUR - GonzÁLez, Muerte y religiosidad..., ob. cit., pág. 212. 
familia». ${ }^{12}$ Las capellanías fueron objeto de disputas toda vez que los testamentos no establecían con nitidez las obligaciones de los beneficiarios o los mecanismos sucesorios. También podían generarse litigios si los encargados de ejecutar la voluntad del difunto (albaceas, patronos, también los propios capellanes) faltaban al cumplimiento de lo que éste dispusiera. La tramitación judicial de las sucesiones y los diversos pleitos desatados en torno a la titularidad sobre los derechos de estas fundaciones, o sobre el pago de las misas a los capellanes, pusieron al descubierto -por encima de cuestiones de índole judicialenfrentamientos íntimamente ligados al control de los bienes hereditarios en los que la propia red familiar se hallaba usualmente involucrada. ${ }^{13}$

En el Montevideo del temprano Ochocientos la capellanía parecía ser casi la única alternativa para asegurar ingresos a un familiar clérigo y también, y aun antes que eso proporcionarle la llave para ingresar formalmente en la estructura eclesiástica. Analizando la campaña de Buenos Aires, Di Stefano ha señalado que la alternativa a la ordenación a título de capellanía era el concurso para alguna parroquia. Pero esta vía, que en Buenos Aires mostraba sus deficiencias, ${ }^{14}$ estaba prácticamente obturada en un territorio como el de la Banda Oriental, donde la débil demografía y el desarrollo lento y tardío de los curatos rurales hacían muy poco factible esta opción. Las posibilidades de «hacer carrera» en términos de alto prestigio social y buen pasar económico eran más que limitadas en unas instituciones eclesiásticas siempre modestas como las montevideanas. ${ }^{15}$

Parte de las singulares circunstancias sociales y económicas que rodearon a estas instituciones en el Río de la Plata se refleja en la trayectoria de dos fundaciones dispuestas por los hermanos Salvador y Domingo Bauzá en el último cuarto del siglo XVIII. A lo largo de varias décadas ambas recorrieron el camino de los tribunales, a veces en medio de ásperos enfrentamientos.

12 José Pedro BARRÁn, La espiritualización de la riqueza. Catolicismo y economía en Uruguay (1730-1900), Montevideo, Ediciones de la Banda Oriental, 1998, p. 56.

${ }^{13} \mathrm{Al}$ centrarnos en dos estudios de caso no es posible disponer de espacio para analizar más detenidamente el contexto económico y jurídico en el que se fundaron las capellanías montevideanas. Véase mayor información en BENTANCOR - BENTANCUR - GONZÁLEZ, Muerte y religiosidad..., ob. cit., pp. 209-216.

14 Roberto DI StEFANo, «Elites, clero e instituciones eclesiásticas en el Río de la Plata (17671835)», ponencia ante las Terceras Jornadas de Historia Económica - Asociación Uruguaya de Historia Económica (AUDHE), Montevideo, 9-11 de julio de 2003, pp. 15-16.

15 Este asunto se aborda más extensamente en BENTANCOR - BENTANCUR - GONZÁLEZ, Muerte y religiosidad..., ob. cit., capítulo 4; también en GonZÁlEZ DEMURO, «Iglesia y crisis monárquica..., ob. cit., pp. 164-167. 


\section{LAS FUNDACIONES DISPUESTAS POR LOS HERMANOS BAUZÁ}

La familia Bauzá estuvo vinculada a la vida montevideana desde el mismo nacimiento de la ciudad. Guillermo Bauzá, militar mallorquín llegado a estas costas en 1729, y Juana García, natural de Canarias e integrante del contingente fundador de la ciudad en 1726, contrajeron matrimonio el 6 de junio de 1736 . Tuvieron al menos 4 hijos: Juana Rosa (nacida en 1740), Domingo, Salvador y Catalina, cuyas fechas de nacimiento se desconocen. ${ }^{16}$ Salvador y Domingo decidieron fundar por vía testamentaria sendas capellanías: el primero falleció soltero en 1778, aunque su proyecto fue llevado a la práctica recién en 1801 . Domingo hizo lo propio en 1792, mandando fundar una obra cuya concreción demoró una década. Los Bauzá no tuvieron actuación particularmente destacada en ningún ámbito de la sociedad montevideana. Salvo algún descendiente de Domingo -como se verá luego-, los miembros de esta familia fueron, si se quiere, personas de cierta solidez económica (no de otro modo podía practicarse una fundación de este tipo) pero sin mayor destaque en la vida pública.

\section{Primer caso: la capellanía fundada por Salvador Bauzá}

Salvador Bauzá testó en artículo de muerte, o para emplear sus propias palabras, «estando enfermo en cama, temiendo de la muerte y su hora incierta», ${ }^{17} \mathrm{el}$ 12 de febrero de 1778. Tras la introducción acostumbrada en estos casos, que incluye invocación a Dios y declaración de fe católica, el testamento se divide en once cláusulas: encomendación del alma, solicitudes sobre formas de funeral y entierro, nombramiento del albacea -Pedro de Barrenechea-, mandas, identificación de acreedores y deudores, fundación de una capellanía y nombramiento de herederos y sus beneficios. Es un documento de mediana extensión, con la notable salvedad de los apartados referidos a la fundación de la obra piadosa, en particular el octavo, que ocupa más de seis de sus once páginas. Junto al noveno, también dedicado a este tema, abarcan las dos terceras partes de toda la pieza, lo que ciertamente nos dice mucho acerca de la trascendencia que para Salvador tenía este asunto.

${ }^{16}$ Los datos sobre la familia Bauzá se extraen de Juan Alejandro ApolAnt, Génesis de la familia uruguaya. Los habitantes de Montevideo en sus primeros 40 años. Filiaciones, ascendencias, entronques, descendencias, Montevideo, Instituto Histórico y Geográfico del Uruguay, 1966, pp. 119, 121, 189 y 529.

${ }_{17}$ Archivo General de la Nación (Montevideo) - Fondo Archivos Judiciales - Protocolos de la Escribanía Pública (en adelante AGN AJ PEP), 1778, tomo 1. Testamento de Salvador Bauzá, 12 de febrero de 1778 (en adelante Testamento de Salvador Bauzá), foja 18. Toda la documentación citada en este trabajo está fechada en Montevideo.

Hispania Sacra, LXIII

127, enero-junio 2011, 261-282, ISSN: 0018-215-X 
La cláusula octava estableció la fundación de una capellanía colativa «compuesta de la cantidad principal de tres mil pesos que sirva perpetuamente en la Iglesia Matriz de esta Ciudad», el más importante templo montevideano. Esta fundación estaba dotada de sus «casas y posesiones», a saber dos fincas y un terreno en la ciudad que no podrían «ser vendidas ni enajenadas en ningún tiempo». ${ }^{18} \mathrm{~A}$ esos inmuebles sumaba otra dotación de quinientos pesos que puestos «a réditos en fincas y persona segura» debían ser destinados a solventar los gastos de mantenimiento de las mencionadas propiedades. Este aspecto era con frecuencia muy tenido en cuenta por los fundadores de capellanías, particularmente interesados en que lo invertido no perdiera valor monetario.

Como capellanes beneficiarios de esta fundación, Salvador llamaba en primer término a su primo hermano Salvador Ponciano García, «hijo legítimo de mi Tío Agustín García [hermano de su madre] y Thomasa López». En segundo lugar se mencionaba otro de los hijos de Agustín, Benito Francisco, «y a falta de éstos en tercero lugar instituyo por tal Capellán a Pedro [Celestino] ${ }^{19} \mathrm{mi}$ sobrino hijo legítimo de mi hermano Domingo Bauzá y Doña Ana Álvarez y a falta de los tres sean capellanes los hijos y descendientes legítimos de mi parentela, y apellidos de Bauzá y García prefiriendo el de mayor edad al que fuere menor». ${ }^{20}$

Esta fundación de Salvador Bauzá tendía a estructurar otra de las «cadenas de tíos y sobrinos [y primos, podría agregarse] que pueblan el clero rioplatense» de finales del período colonial, como ha señalado Di Stefano. ${ }^{21}$ Luego se verá que la obra de Domingo Bauzá acentuó aún más este perfil.

Como patronos fueron designados el «referido Tío D. Agustín García y por falta de éste a mi hermano D. Domingo Bauzá, y por la de ambos a mis descendientes o Parientes prefiriendo en ello el de mayor edad» (VÉASE CUADRO NÚMERO 1). Agustín fue nombrado finalmente como heredero universal «en el remanente de todos [los] bienes» del benefactor, una vez «cumplido este testamento, mandas, legados y declaraciones en él hechas».22

Podría decirse que la de esta obra piadosa fue una historia de dilaciones, abusos y renuncias. Porque si bien Salvador manifestó claramente su deseo de

18 Testamento de Salvador Bauzá, fojas 19-20.

${ }^{19}$ Aunque Bauzá menciona a «Pedro José» es evidente que se trata de un error o de un tercer nombre de pila de Pedro Celestino Bauzá; la firma que aparece al pie de la renuncia a la capellanía que Pedro firmaría en 1810 así lo demuestra. AGN AJ PEP, 1810, tomo 1, Renuncia del derecho de capellán que hace Don Pedro Bauzá en su hermano Don Andrés (en adelante Renuncia de Pedro Bauzá), 15 de marzo de 1810 , foja 168 vta.

${ }^{20}$ Testamento de Salvador Bauzá, fojas 20 y 20 vta.

${ }^{21}$ DI STEFANO, «Elites..., ob. cit., p. 12.

22 Testamento de Salvador Bauzá, fojas 22 y 23. 
que «después de [sus] días» las autoridades eclesiásticas tuvieran «por fundada esta capellanía en las condiciones [...] aquí expresad[a]s»,23 la tramitación se hizo con gran lentitud. El primer patrono, Agustín García, falleció el 30 de octubre de 1779..$^{24}$ El encargado de suplirlo, Domingo Bauzá, no solamente incumplió el deseo de su hermano de proceder a una inmediata fundación sino que tanto él hasta su fallecimiento en 1792, como sus herederos -en especial su viuda y albacea Ana Álvarez- retuvieron los réditos durante muchos años. Debido a ello Salvador Ponciano García, capellán titular, recurrió a la justicia reclamando el pago correspondiente..$^{25}$

En 1799 este sacerdote se presentó ante el juez civil denunciando que la familia Bauzá «no rindió cuentas desde diciembre de 1779 a pesar de [sus] reiteradas reconvenciones» para que cumpliera con sus obligaciones. Decía «no hab[er] percibido sino una corta parte de aquellas obvenciones por vía de alimentos [...] desde el pasado año de [17]79 hasta 13 de junio de [17]92 en que [Domingo] murió», considerando «intolerable la morosidad de dicha Doña Ana [Álvarez]». La justicia exigió a los Bauzá que informaran de lo actuado con documentos a la vista. Resultó que adeudaban al capellán la nada despreciable suma de 1225 pesos 2 reales. En cambio, otros 583 pesos en alimentos, ropas y dinero para el pago de unas refacciones ya habían sido desembolsados. ${ }^{26}$

El proceso de partición de bienes siguió su lento curso, hasta que en 1802 estuvo todo dispuesto para que los herederos recibieran sus hijuelas. Tal vez guiado por la experiencia anterior, Salvador Ponciano consideró muy poco conveniente presentarse ante cada uno de ellos a cobrar su porción de la deuda. Encontró un camino más corto: ante el juez declaró que habiendo recibido la noticia de que «la casa principal de la testamentaría se [iba] a vender [...] en pública almoneda [se presentaba] el mejor medio y el más proporcionado para que, sin necesidad de ejecuciones ni otras diligencias» se efectuara «el pago de los 1225 pesos 2 reales que se [1]e deb[ía]n». ${ }^{27}$ La venta se llevó a cabo en febrero de 1803 y el 5 de junio el capellán logró por fin reunirse con su dinero, 25 años después del fallecimiento del fundador. ${ }^{28}$

\footnotetext{
${ }^{23}$ Testamento de Salvador Bauzá, foja 22.

24 Apolant, Génesis..., ob. cit., p. 357.

${ }^{25}$ Resulta paradójica la gran confianza que Salvador tenía en su hermano Domingo; recomendó al albacea atender sin dudar todos sus reclamos, subrayando «la mucha satisfacción que me asiste de su Cristiano proceder». Testamento de Salvador Bauzá, foja 19.

${ }^{26}$ Archivo General de la Nación (Montevideo) - Fondo Archivos Judiciales - Expedientes del Juzgado Civil $1^{\circ}$ (en adelante AGN AJ Civil $1^{\circ}$ ), caja 135, expediente 47, año 1799, Don Salvador García, sobre que rinda cuentas Doña Ana Álvarez del patronato de la capellanía instituida por Don Salvador Bauzá, hermano de su finado esposo y ella como albacea del finado su esposo Don Domingo [Bauzá] (en adelante Salvador García contra Ana Álvarez), fojas 9, 15, 18-23.

${ }^{27}$ Salvador García contra Ana Álvarez, fojas 34-38.

${ }^{28}$ Salvador García contra Ana Álvarez, fojas 40 y 42.
} 
Pero otros movimientos ya se habían producido. Dos años antes, el 4 de mayo de 1801, la capellanía era formalmente fundada por intermedio del patrono sucesor de Domingo Bauzá, Felipe Santiago García, un hermano de Salvador Ponciano y Benito Francisco que fue confirmado en el cargo por el juez eclesiástico en febrero de 1798 luego de una corta disputa entre él y Pedro Celestino Bauzá. ${ }^{29}$ En este como en muchos otros casos similares las sucesivas dilaciones tuvieron como consecuencia no deseada la pérdida de una porción del patrimonio fundacional. Salvador Bauzá había dispuesto que otra de sus propiedades, «una tahona que tengo [...] en el fondo del terreno de dichas mis casas» ${ }^{30}$ se constituyera en bien «de reserva» para el caso de que el valor de las dos casas y el terreno no llegara por lo menos a 3000 pesos. Fue una previsión que se confirmó en la práctica, ya que esos bienes fueron tasados en poco más de 3130 pesos, pero deducidos 337 pesos con 71/2 reales de distintas reparaciones hechas en esos inmuebles la cifra final cayó a 2794. ${ }^{31}$ Sin embargo, para ese entonces la tahona ya había sido «destruid[a] por la injuria de los tiempos». El terreno sobre el que había estado construida fue entonces el recurso movilizado para así alcanzar la suma prefijada. ${ }^{32}$

Los primeros tres capellanes convocados renunciaron, dos de ellos antes incluso de acceder al beneficio. Aunque no era habitual una acumulación como la de este caso, las dimisiones no fueron extrañas y se tornaron cada vez más frecuentes en el Río de la Plata a medida que los empujes secularizadores aumentaron. Los motivos eran variados; por ejemplo, algunos de los potenciales capellanes eran muy jóvenes al momento de promoverse una fundación en su beneficio y llegada la edad de iniciar los estudios elegían emprender otro camino. Otras veces, con su formación ya en marcha, cambiaban de parecer y optaban por otras carreras o por la formación de una familia. La trayectoria de estas obras piadosas tuvo directa relación con la evolución de las vocaciones sacerdotales y las relaciones clero regular y secular, cuestión importante sobre la que

\footnotetext{
${ }^{29}$ AGN AJ PEP, 1801, tomo 1, Venta de terreno de Don Felipe Santiago García a su hermano Don Salvador (en adelante Venta de terreno), 2 de mayo de 1801, foja 261. Pedro Celestino fue un importante hacendado en la zona de Canelones, aledaña a Montevideo, que colaboró con el financiamiento de la revolución iniciada en 1811 bajo el mando de José Artigas.

30 Testamento de Salvador Bauzá, foja 22 vta.

${ }^{31}$ AGN AJ PEP, 1801, tomo 1, Fundación de Capellanía. Don Felipe Santiago García a favor de su hermano Don Benito Francisco (en adelante Felipe Santiago García a favor de su hermano Benito), 4 de mayo de 1801, fojas $276 \mathrm{vta}-277$.

${ }^{32}$ La participación de miembros de la familia García se amplió todavía más en toda esta tramitación. Según la escritura fundacional, Tomás Francisco García (hermano de los dos aspirantes a la capellanía y del patrono), actuó como apoderado de Felipe Santiago en la presentación de un reclamo por deudas contra la sucesión Bauzá. Felipe Santiago García a favor de su hermano Benito, foja 276 vta.
} 
no podemos extendernos aquí y merecedora de mayores estudios para el caso de la Banda Oriental. ${ }^{33}$

Veamos el caso del primer miembro de la familia García llamado a ocupar esta capellanía. Salvador Ponciano ya había renunciado a su carrera sacerdotal ${ }^{34}$ y por ende al beneficio que le otorgara su primo cuando logró cobrar los 1225 pesos a que se hizo mención anteriormente. El 22 de abril de 1801 (doce días antes de fundarse la capellanía) manifestó ante un juez civil que «después de hechas sus reflexiones [comprendió] no querer ordenarse». Se esmeró en destacar el carácter indeclinable de su dimisión: «se obliga[ba] a no revocar[la] ni reclamar total ni parcialmente [...] y si lo hiciere a más de no ser oído ni admitido judicial ni extrajudicialmente [fuera] condenado por el mismo caso». 35

Aparece aquí un elemento de interés: la renuncia estuvo acompañada de otros movimientos que reforzaron el costado material y familiar del proyecto piadoso. Apenas dos semanas después de su apartamiento, Salvador Ponciano compró a Felipe Santiago un terreno que formaba parte del capital fundacional de la capellanía. Estaba avaluado en 1025 pesos. Acordaron una fórmula de pago según la cual una parte se haría en efectivo ( 687 pesos $1 / 2$ real), considerando los restantes 337 pesos con $7 \frac{1}{2}$ reales ya pagos, según va dicho, en refacciones. ${ }^{36}$ La documentación existente demuestra que ese mismo día el comprador tomó «a censo redimible» (o dicho de otro modo, en préstamo) los 500 pesos adicionales con que Salvador Bauzá había dotado a su capellanía, imponiéndolos «sobre todos [sus] bienes [...] con especialidad sobre un terreno solar que este otorgante tiene», es decir el que acababa de comprar al patrono de la capellanía. ${ }^{37}$ La escritura de imposición era sumamente clara: siempre que cumpliera con la obligación de pagar al patrono el 5\% anual sobre el monto acensuado, vale decir, 25 pesos, el comprador tenía garantizado el más absoluto dominio sobre el terreno, sin que nadie pudiera formular ningún tipo de reclamo. ${ }^{38}$

\footnotetext{
${ }^{33}$ Con su habitual solidez, Barrán ha avanzado en la profundización de este tema y en el planteamiento de nuevas hipótesis de trabajo en La espiritualización de la riqueza... ob. cit., pp. 105-116. Para el caso de la región rioplatense en general, y bonaerense en particular, son de gran interés trabajos como el de María Elena BARRAL, De sotanas por la Pampa: religión y sociedad en el Buenos Aires rural tardocolonial, Buenos Aires, Prometeo, 2007, pp. 29-48, y Roberto DI STEFANo, «Abundancia de clérigos, escasez de párrocos: las contradicciones del reclutamiento del clero secular en el Río de la Plata (1770-1840)», en Boletín del Instituto de Historia Argentina y Americana «Dr. Emilio Ravigna$n i », \mathrm{n}^{\circ}$ 15-16 (2do. Semestre de 1997 - 1er. Semestre de 1998), passim.

${ }^{34}$ En enero de 1809 contrajo matrimonio con Juliana Chiribao (APOLANT, Génesis..., ob. cit., p. 295).

${ }_{35}$ AGN AJ PEP, 1801, tomo 1, Repudiación y renuncia de capellán. Don Salvador García a favor de su hermano Don Benito, 22 de abril de 1801, fojas 246 vta -247 .

${ }^{36}$ Venta de terreno, foja 262.

${ }^{37}$ AGN AJ PEP, 1801, tomo 1, Imposición de censo. Don Salvador Ponciano García a favor de la Capellanía fundada por Don Salvador Bauzá (en adelante Imposición de censo), 2 de mayo de 1801, fojas 266 vta -267.

${ }^{38}$ Imposición de censo, fojas 267 vta - 268.
}

Hispania Sacra, LXIII

127, enero-junio 2011, 261-282, ISSN: 0018-215-X 
En síntesis, Salvador Ponciano había acordado pagar 687 pesos $1 / 2$ real en efectivo, pero de inmediato recibió del patrono 500 pesos con la única condición de pagarle anualmente los intereses. Así las cosas, en el momento de la compra debió desembolsar nada más que 187 pesos $1 / 2$ real por un terreno tasado, según se ha visto, en 1025. Esto significa que aun renunciando a su calidad de sacerdote y primer capellán encontró los medios idóneos para beneficiarse de la fundación ordenada por su primo Salvador Bauzá. La familia García asumía así un control cada vez más firme sobre el patrimonio espiritualizado: uno de los hermanos era el patrono (Felipe Santiago), otro el capellán (Benito Francisco), y un tercero, Salvador Ponciano, era ahora propietario de uno de los inmuebles que servían de sustento a la fundación. Se producía de esta forma la mixtura entre espiritualización de riquezas y ejercicio del control sobre ellas, adicionando un componente de prestigio social como el de asegurar la carrera sacerdotal a un miembro de la familia.

Pero regresando a la cuestión de las renuncias se advierte que tampoco Benito permaneció mucho tiempo como titular. En julio de 1809 fue llamado al goce de este beneficio por «su primo hermano y Padrino», y aunque «aspir[ó] siempre a[1 sacerdocio]» había «desistido de la idea que había formado de seguir por [esa] carrera» y optaba por ceder su lugar a quien «deb[ier]a suceder[le]»..$^{39}$ El nuevo beneficiario resultaba ser Pedro Celestino Bauzá, sobrino del instituyente, que en 1810 también declinó por hallarse sin «intento de seguir por la carrera de sacerdocio». Presentó «voluntaria renuncia y abdicación» en favor de su hermano Andrés de la Cruz, a quien correspondía convocar según el testamento de Salvador. ${ }^{40}$ Un factor de carácter tan personal como la falta de vocación religiosa acarreó en este caso dos consecuencias relevantes: accedió a la titularidad un miembro de la familia Bauzá, y éste fue además, durante casi una década, capellán de la fundación ordenada por su padre Domingo, como se verá en el siguiente apartado.

\section{Segundo caso: la capellanía fundada por Domingo Bauzá}

El testamento de Domingo Bauzá está fechado 6 de junio de 1792. Ordenó su fundación en los siguientes términos: «declaro es mi voluntad que del quinto de mis bienes se funde una capellanía, de cantidad de cuatro mil pesos en caso de alcanzar dicho quinto y de no de la cantidad que este alcance, para que a título de ella se ordene mi hijo Andrés y en su defecto, cualesquiera de los otros

${ }^{39}$ AGN AJ PEP, 1809, tomo 2, Renuncia que hace Don Benito García de un nombramiento de Capellanía, 11 de julio de 1809 , foja 522 vta.

${ }^{40}$ Renuncia de Pedro Bauzá, foja 168 vta. 
mis hijos que quiera seguir la Iglesia por el estado Eclesiástico, y en defecto de estos vaya sucediendo a mis nietos y descendientes con la pensión de decir veinticinco misas al año ${ }^{41}$ [nombrando] por patrono de esta Capellanía a mi legítima esposa doña Ana Álvarez, en segundo lugar para mi hijo Pedro y luego deberá recaer su patronato en el cura y vicario, que fuese o sea sucesivamente de esta santa Iglesia Matriz, con advertencia que la citada capellanía se ha de fundar como dejo dicho del quinto de mis bienes, y que el Capellán ha de entrar desde luego al goce de ella y mientras no se ponga en actitud de ordenarse de sacerdote, haya solamente de mandarse decir anualmente las misas que quedan dispuestas». 42

Nótese que el testador señaló como primer favorecido específicamente a Andrés de la Cruz, el mayor de sus hijos varones aspirantes al sacerdocio, precisión que no mantuvo al fijar el orden sucesorio («en su defecto, cualesquiera de los otros mis hijos que quiera seguir la Iglesia por el estado Eclesiástico»). Esta laxitud abriría las puertas a futuras discusiones laudadas por la vía judicial.

Domingo Bauzá tuvo una familia numerosa: su esposa Ana Álvarez (albacea y patrona de la capellanía), y ocho hijos: Pedro Celestino (designado segundo patrono), Andrés de la Cruz, Domingo Román, Guillermo Bruno, Ana Tomasa, Francisco Solano, Simona Tadea y Rufino José (vÉASE CUADRO NúMERo 2). Nombró como herederos universales a todos ellos «por iguales partes, para que lo hallen, hereden y gocen con la bendición de Dios y la mía». Su proyecto piadoso también se vio demorado: Ana no concretó la fundación hasta 1802, actuando por intermedio de su segundo esposo, Hilario José Sánchez.

Antes de practicar la fundación, Sánchez debió llevar a cabo los deslindes patrimoniales. En efecto, la casa en la que se afianzaba el principal era una propiedad de la familia tasada en 4287 pesos, cifra más que suficiente para cumplir con la voluntad de Domingo. Pero «t[enía] el capellán Don Andrés [...] en dicha finca pertenecientes a su herencia» la suma de 388 pesos con $2 \frac{1}{1} 2$ reales que era preciso restituirle. La instancia judicial garantizó el disfrute de su patrimonio personal al joven sacerdote. Siendo clérigo no debía hacer votos de pobreza como hacían los regulares, de modo que estaba en condiciones de testar y administrar como un laico los bienes familiares y personales ${ }^{43}$ Se determinó «como corresponda [...] reintegrarle [a Andrés] su legítimo haber paterno [...] man$\mathrm{da}[\mathrm{ndo}]$ se le $\mathrm{h}$ [iciera] entrega de las varas de terreno correspondientes al fondo

\footnotetext{
${ }^{41} \mathrm{Su}$ hermano Salvador había dispuesto idéntica carga: «Veinte y cinco misas rezadas en los días de las Festividades del Señor y de la Santísima Virgen María [etc.]». Testamento de Salvador Bauzá, fojas 21 vta - 22.

42 AGN AJ PEP, 1792, t. 1 (2), Testamento de Domingo Bauzá (en adelante Testamento de Domingo Bauzá), 6 de junio de 1792, fojas 67 vta. - 70.

43 DI STEFANO, «Elites...», ob. cit., p. 13.
} 
de la casa [...] que equival[ieran] por su tasación al pago de los 388 pesos [...] y separarse de aquella casa», que quedaría afectada al mantenimiento de la capellanía que lo tendría como titular. ${ }^{44}$

Andrés de la Cruz fue capellán hasta su fallecimiento en 1818, momento en el que su hermano Guillermo accionó ante la justicia defendiendo los derechos de uno de sus hijos, Guillermo Isidoro. Aunque el difunto se había propuesto llevar a cabo la toma formal de posesión no alcanzó a cumplir con todas las disposiciones legales, pese a lo cual igualmente su familia aceptó el goce irregular del beneficio «por convenio amistoso y consideraciones hacia su persona por [sus] escasos recursos». ${ }^{45} \mathrm{Se}$ ha señalado más arriba que el fundador no determinó con precisión el orden sucesorio, por lo que desaparecido el primer titular quedó abierto el camino a las disputas. Ninguno de los hermanos de Andrés de la Cruz optó por seguir la carrera eclesiástica; el legítimo aspirante podía ser entonces alguno de los nietos de Domingo. Mientras ninguno de ellos contara con edad y formación suficiente ${ }^{46}$ las misas serían oficiadas -como era habitual en tales casos- por curas pagados por el patrono, que era por entonces el Cura Vicario de Montevideo, Dámaso Antonio Larrañaga, dadas las ausencias de los dos primeros nominados por Domingo Bauzá. ${ }^{47}$ Por último, el capellán debía ser electo entre dos nietos de Domingo: Federico Bauzá, hijo de Francisco y Petrona Tristán, y Guillermo Isidoro, hijo de Guillermo y reconocido desde 1818 como legítimo sucesor de Andrés de la Cruz. En efecto, la justicia dispuso en setiembre de dicho año que Fidel Rey, ocupante de la casa en que estaba afianzada la capellanía y apoderado de Andrés, ${ }^{48}$ entregara a Guillermo Bauzá el producido de los alquileres ( 25 pesos mensuales).

Luego de varios años de dilaciones, el pleito se inició formalmente en 1830. Ambos jóvenes eran menores de edad y comparecieron ante los tribunales representados por sus padres. El 8 de febrero Petrona Tristán presentó un escrito ante el Juez en lo Civil, reclamando para su hijo el disputado beneficio. Basó su argumento en el hecho de que Federico era mayor que su primo Guillermo Isi-

${ }^{44}$ AGN AJ Civil $1^{\circ}, 1802$, caja 146, expediente 13, Fundación de capellanía, fojas 11-13.

45 AGN AJ Civil $1^{\circ}, 1818$, caja 189, expediente 34, Expediente promovido por Don Guillermo Bauzá, reclamando la posesión en favor de un hijo suyo de la Capellanía que dejó su finado Padre Don Domingo Bauzá, y usufructuaba el hijo de este Don Andrés ya finado, foja 1.

${ }^{46} \mathrm{La}$ edad fijada por la legislación tridentina era de 22 años para acceder al subdiaconado, 23 para el diaconado y 25 años para el presbiteriado. Sin embargo, no fue extraño que estos requisitos (así como el nivel formativo de los nuevos sacerdotes) experimentaran variaciones en distintas zonas del imperio hispánico. Una correcta síntesis de estas diversidades aparece en Arturo MorGADO GARCíA, Ser clérigo en la España del Antiguo Régimen, Cádiz, Servicio de Publicaciones de la Universidad de Cádiz, 2000, pp. 49-57.

${ }^{47}$ Ana Álvarez, su viuda, estaba en Buenos Aires, y Pedro Celestino había fallecido.

48 AGN AJ PEP, 1810, tomo 1, Poder general que otorga Don Andrés de la Cruz Bauzá a Don Fidel Rey, [1810], fojas 55 vta - 56 vta. 
doro, lo que según su parecer otorgaba mayores derechos. Agregó que «siendo tan fuertes y sólidos los argumentos en que se apoya[ba], y tan ridículos como absurdos los que opon[ía] el Don Guillermo para destruirlo[s, el] Juzgado se ha[bría] de servir no hacer lugar» al desconocimiento de sus derechos tal como Guillermo solicitaba. ${ }^{49}$

Bauzá sostenía que el matrimonio entre su extinto hermano Francisco y Petrona era ilegítimo, de lo cual se derivaba la imposibilidad de reclamar derecho alguno sobre la citada capellanía. El seguimiento de esta discusión nos introduce en otros asuntos más generales y no menos importantes, como la creciente disputa que tras la revolución se instaló entre los fueros civil y eclesiástico en la sociedad rioplatense.

Según Francisco Araúcho (escribano que actuaba en nombre de Tristán), Santiago Figueredo, «el sacerdote que existía en la División del General [José] Artigas y que ejercía las funciones anexas a su ministerio fue el que en presencia de dos testigos autorizó» dicha unión en 1812. Agregaba que «esto es lo que importa en los actos civiles y es lo único que debe consultar el juzgado quien [...] no ha decidido ni ha podido decidir sobre la legitimidad o ilegitimidad del matrimonio sino sobre la validez y sus efectos civiles».

Su oponente -representado por Juan Villorado- enfatizó en la nulidad de aquel acto dadas las omisiones de carácter legal en que incurrieran Tristán y su esposo: los comprobantes aportados por la litigante «han sido traídos de un Estado Extranjero, ${ }^{50}$ sin la legalización que por estilo y práctica de los tribunales, debían tener, para no ser redargüidos de falsos, en conformidad a lo dispuesto por la ley 115, tít. 18 part. 3 [sic], y que finalmente fueron desechados como sospechosos por mi instituyente». Avanzó luego en una reivindicación del fuero civil en este pleito: «Ningún matrimonio puede producir efecto alguno civil sin que aparezca como civilmente cierto [...]. La ley 6, tit. 2 part. 4 [sic] expresamente dice que 'Casar pueden todos aquellos que han entendimiento sano... fueras aquellos a quienes defiende el derecho, señaladamente, que non puedan casar'. Don Francisco Bauzá era primo hermano de Doña Petrona Tristán. El derecho así canónico como Civil prohíben estos enlaces de una manera bastante fuerte y vigorosa».

\footnotetext{
${ }^{49}$ AGN - Fondo Archivos Particulares, caja 327, carpeta 9. Expediente relacionado con la Capellanía que pertenecía a Domingo Bauzá y litigio que originó (1827-1841) (en adelante Expediente capellanía Domingo Bauzá), fojas 1 - 1vta.

${ }^{50}$ La documentación había sido expedida en la ciudad de Buenos Aires. En 1830, al desatarse este pleito, la República Argentina y el Estado Oriental (más tarde República Oriental) del Uruguay eran ya formalmente dos países diferentes pero no así en 1812, cuando la Oriental era una más de las provincias rioplatenses.
} 
Enseguida cuestionó tanto lo actuado como -más sutilmente- lo querido por el cura Figueredo en 1812: «prescindo por ahora de entrar en el análisis de las facultades que podía o no tener [el presbítero] y de si eran o no súbditos de éste los que se dicen desposados por él» aunque creía necesario detenerse en «las tramoyas y manejos secretos que se han empleado para hacer aparecer como casados a los que jamás aspiraron tal vez a esta noble jerarquía». Sugería la existencia de un plan urdido entre los contrayentes y el sacerdote, que a sabiendas de la ilicitud de aquel acto buscaban beneficios de otro tenor. Semejante maniobra tenía para Villorado consecuencias claramente favorables a su cliente también en la órbita eclesiástica: «donde no existe matrimonio, sin cuestión, no puede haber ese bien de linaje "que es el de facer fijos para acrescer derechamente el linaje de los Omes, que con tal entención deven casar'». Este matrimonio no era «incuestionable» y por tanto sus hijos no eran «capaces de acrecentar el linaje».51

En defensa de su tesis Araúcho se aferró al esquema diocesano vigente en el Río de la Plata y antepuso los efectos civiles del casamiento a los religiosos: la jurisdicción del obispado de Buenos Aires sobre Montevideo daba toda la legitimidad necesaria. «Porque no se hubieran llenado ciertas formalidades puramente eclesiásticas, ¿habría de declararse hoy civilmente nulo un matrimonio, después de 18 años de celebrado, privando a su prole de todos sus derechos [...]? Tratamos únicamente de la validez civil del matrimonio [...] porque son puramente civiles los efectos». A esto respondió Villorado: «Es cosa nueva en el Foro, que los Matrimonios para causar los efectos civiles que les otorgan las Leyes, sea innecesario revistan todas las formalidades que deben intervenir en su celebración según las Leyes Canónicas. En países donde la religión Católica [...] es la dominante, no se admiten matrimonios civiles que no son realizados según el rito de la Iglesia», y quien así no lo entendiere «desconoc[ía] del todo [o] hac[ía] una profesión de fe distinta a la que tenemos para atreverse a sostener la doctrina de la Tristán». Concluyó señalando que se estaba ante un impedimento dirimente: «es falso haberse casado la Tristán con Don Francisco Bauzá», y aunque así hubiera acontecido el acto era «írrito y nulo por ser entre primos hermanos, y no haber precedido la correspondiente dispensa por parte de la Autoridad Eclesiástica», unión que «no mere[cía] otro nombre que el de amancebamiento».52

Araúcho trató de poner paños fríos a esta discusión sobre cuestiones de derecho canónico, acusando a su oponente de esgrimir ahora argumentos que no habían sido empleados antes, como el de la presunta nulidad («se contentó con decirlo, y en nada ha pensado menos que en probarlo», acotó). Su respuesta no

\footnotetext{
${ }^{51}$ Expediente capellanía Domingo Bauzá, fojas 10 - 11 vta.

52 Expediente capellanía Domingo Bauzá, fojas 13 - 14 vta.
} 
excluyó cierto tono burlón contra la celosa ortodoxia católica de Villorado y su representado, «celo que de litigante[s] le[s] ha transformado en misionero[s]».53 Finalmente, en junio de 1830 un tribunal integrado por Francisco Llambí y José Ellauri ${ }^{54}$ falló a favor de Petrona, debiendo correr Guillermo con la totalidad de los gastos que ocasionó el pleito. ${ }^{55}$

La situación familiar tuvo de inmediato un nuevo giro. Bauzá y Tristán acordaron no litigar en lo sucesivo. El primero procedió a redimir el capital que estaba afianzado en su casa y que componía el principal de la capellanía fundada por su padre. A esas alturas el valor de los bienes afectados había descendido sensiblemente, como era de esperar luego de tantos años: tras el inventario, la tasación y la partición de bienes, los 4000 pesos inicialmente previstos quedaron en $2721 .{ }^{56}$ Esta fue la cifra que Guillermo devolvió a Petrona «con la condición de que ser[ía]n removidos de [su] casa y colocados sobre otra finca». Ella se comprometía a no «promover gestión alguna [renunciando] todo derecho a la dicha casa de Dn. Guillermo, de la que quedar[ía] legítimo dueño» una vez deducida aquella suma.

Tratándose de una fundación cuyo beneficiario era menor de edad, debieron comparecer ante el Defensor de Menores presentando todos los antecedentes y acompañados por el cura Larrañaga, patrono de la fundación. El magistrado consideró que "propender a evitar un litigio entre hermanos e[ra] un deber sagrado en todo hombre de honradez y probidad». Tampoco halló motivos legales para impedir el traslado del principal a otra casa, y el 23 de octubre de 1830 autorizó la operación. ${ }^{57}$

Acordado esto surgió una nueva dificultad. Como ya venía sucediendo en Buenos Aires, también en Montevideo las casas en buen estado se hallaban en su mayoría gravadas con hipotecas, por lo que no se hallaba fácilmente una en la que afianzar el dinero devuelto por Guillermo. ${ }^{58}$ La solución encon-

${ }^{53}$ Expediente capellanía Domingo Bauzá, fojas 16 - 16 vta.

${ }^{54}$ Ellauri y Llambí fueron dos importantes miembros de la elite doctoral montevideana. Integraron la Asamblea Constituyente que entre 1828 y 1829 elaboró el texto de la primera Constitución del nuevo Estado independiente, que fue jurada el 18 de julio de 1830 .

55 Expediente capellanía Domingo Bauzá, fojas 18-22. Quedó registrado además que Llambí y Ellauri cobraron por esta tarea 17 pesos cada uno.

${ }^{56}$ Expediente capellanía Domingo Bauzá, fojas 1, 25 - 25 vta, 27-28.

${ }^{57}$ Expediente capellanía Domingo Bauzá, fojas 23 y 31 vta.

${ }^{58}$ Susan Socolow, Los mercaderes del Buenos Aires virreinal: familia y comercio, Buenos Aires, Ediciones de la Flor, 1991, p. 122. «El uso de la propiedad urbana condujo eventualmente al deterioro [de la misma] o a su venta forzada para enfrentar los compromisos de la capellanía», señala la autora. Evidentemente éste era también el caso de Guillermo Bauzá. Véase el estudio de esta problemática en el México virreinal en Gisela von WoBeSER, «La función social y económica de las capellanías de misas en la Nueva España del siglo XVIII», Estudios de Historia Novohispana, 16 (Universidad Nacional Autónoma de México - Instituto de Investigaciones Históricas, 1996), pp. 131-132. 
trada fue vender la vivienda en la que estaba depositado el capital, mecanismo al que se recurría «para evitar morosidades y dilaciones que pu[dier]an entorpecer la conclusión de [dicha] transacción». Contaban con un promitente comprador (Tomás Casares) dispuesto a hacerse cargo del pago de los intereses correspondientes al mantenimiento de la capellanía. El inmueble estaba tasado en 2000 pesos pero el interesado pagó 4721 , esto es la suma del valor estimado y el capital redimido. En enero de 1831 se efectuó la transacción.

Nuevas instancias judiciales esperaban a la capellanía de Domingo Bauzá. A finales de la década entró en escena Rufino, el más famoso de sus hijos. Participante activo en el levantamiento de 1811, fue Capitán de Blandengues y fiel aliado de José Artigas en los primeros años de la revolución. Organizó el Batallón de Libertos (conocido entonces como «los Negros de Bauzá») con el que enfrentó a los invasores portugueses en 1816. En 1817 se alejó de las filas artiguistas debido a sus discrepancias con el caudillo federalista y se radicó primero en Buenos Aires y luego en la provincia de Santa Fe, hasta que en 1829 regresó a Montevideo. Ocupó importantes cargos militares durante el primer gobierno del Uruguay independiente, presidido por Fructuoso Rivera entre 1830 y 1834. Durante la llamada «Guerra Grande» (1838-1851) fue Ministro de Guerra del gobierno de Montevideo, Comandante General de Armas y Presidente del Consejo de Estado.

Rufino tenía un año de edad cuando su padre ordenó la fundación que ahora despertaba su interés. El 19 de enero de 1839 solicitó copia del expediente formado durante el pleito entre su hermano Guillermo y Petrona Tristán con el objetivo era iniciar acciones reclamando para su hijo Rufino Francisco la titularidad de la capellanía instituida en $1792.5^{59}$ Ninguno de los cuatro hijos de Petrona y Francisco habían optado por el sacerdocio («unos se han casado y otros han escogido carrera», afirmaba su madre). Tanto Federico (en cuyo nombre había querellado Petrona) como Fabián, los únicos de esta familia que conservaban algún derecho sobre la fundación, renunciaron formalmente tras el reclamo de su tío. Se debía necesariamente «pasar dicha capellanía a [...] los hijos del Señor General Dn. Rufino Bauzá [y en particular a] Rufino Francisco que [...] se halla[ba] siguiendo sus estudios en el Colegio de los Escolapios de esta Ciudad».60

Resulta interesante analizar aquí las acciones posteriores de Rufino respecto de dos asuntos: las propiedades inmuebles que respaldaban la disputada obra piadosa, y la concepción de capellanía que tales actos revelan. Cuestionó radicalmente la

${ }^{59}$ El hermano de Rufino Francisco y segundo hijo de Rufino fue el historiador y periodista Francisco Bauzá, autor de la muy difundida Historia de la dominación española en el Uruguay, uno de los textos fundacionales de la historiografía uruguaya, publicado entre 1880 y 1882 .

${ }^{60}$ Expediente capellanía Domingo Bauzá, fojas 36 - 37 vta., 39, 40 y 41. 
venta del inmueble hecha por su hermano Guillermo en 1831, interpretando la enajenación -más allá de la recuperación de los 2721 pesos - como una violación de lo establecido en un documento de $1819 .{ }^{61}$ De acuerdo con ello la venta podía juzgarse ilegal y exigió que fuera «declarada ipso iure nulla».62

Es muy singular la concepción de bien capellánico contenida en el escrito presentado por Rufino. Al reclamar al juez la devolución a su hijo de la casa enajenada y los réditos generados, sostuvo que «no se trata[ba] del simple patronato de una capellanía [sino de que] la capellanía no es ni una hipoteca ni un censo, sino que es la misma finca según la cláusula institutriz [y] por consiguiente no venía a reclamar los réditos o el censo de esa capellanía, sino la capellanía misma, que es la casa». Por si alguna duda quedaba se anticipó a exigir que «no se [le hiciera] la objeción confundiendo[s]e la capellanía con sus réditos, porque éstos ser[ía]n los que d[iera] la finca». ${ }^{63}$

Esta interpretación reformulaba el concepto de capellanía, que dejaba de ser una fundación piadosa en la que los bienes materiales eran vehículo necesario para el logro de objetivos espirituales para convertirse en un bien material específico que proporcionaba recursos económicos a su usufructuario. La obra piadosa, como institución, era confundida con un determinado patrimonio que le daba sustento. La decidida acción de Bauzá para hacer retornar al círculo familiar no ya los réditos sino la propia fuente de los mismos sugiere que para el reclamante la finca en cuestión era más bien una propiedad vinculada, indivisible, a ser protegida de la dispersión. En este caso, por tratarse de una capellanía laical, el inmueble constituía un patrimonio vinculado ${ }^{64}$ que Bauzá trataba de mantener dentro del ámbito familiar.

Rufino no logró el reintegro del inmueble pero sí la traslación del principal a su propia finca, cuyo valor -algo más de 10600 pesos $^{65}$ - excedía largamente la inversión original. De modo que lo destinado a esta obra por Domingo Bauzá en 1792, casi cincuenta años más tarde era reintegrado al patrimonio de uno de sus herederos.

61 «La misma finca [...] no ha de poder enajenarse, dividir, acensuar, hipotecar ni gravar, en todo o en parte aunque lo intent[ara]n los Capellanes y lo consi[ntier]an así los Patronos pretextando mayor aumento de renta u otra cosa por grave o urgente que [fuera]». Archivo de la Curia Eclesiástica de Montevideo - Fondo Archivo Histórico - Capellanías (en adelante AC FAH C), carpeta 43. Don Guillermo Bauzá solicitando se le permita vender porción de suelo del fundo de una Capellanía, [1819], foja 7 vta.

62 Expediente capellanía Domingo Bauzá, fojas 43 - 43 vta. Subrayados en el original.

${ }^{63}$ Expediente capellanía Domingo Bauzá, fojas 44 - 45.

64 Véase Juan Pro RuIz, «Las capellanías: familia, Iglesia y propiedad en el Antiguo Régimen», Hispania Sacra, 41 (1989), pp. 596-597.

${ }^{65}$ El certificado de medida y tasación de este inmueble (expedido el 12 de mayo de 1841) está archivado en AC FAH C, carpeta 43. Don Rufino Bauzá: sobre traslación de la Capellanía que fundó su Sr. Padre Don Domingo Bauzá de 2700 pesos, [1841], foja 3.

Hispania Sacra, LXIII

127, enero-junio 2011, 261-282, ISSN: 0018-215-X 


\section{EN SÍNTESIS}

Las capellanías de misas, notablemente expandidas en el mundo católico a partir del siglo XVI, adquirieron en la sociedad montevideana del Ochocientos un tono peculiar. Al igual que en España y sus otras posesiones americanas funcionaron como un medio idóneo para mantener dentro de la estructura familiar una parte importante del patrimonio. Se confirma en los casos que acabamos de ver, que tanto la institución como el bien, la fundación y el elemento físico que le servía de sustento, constituyeron bienes vinculados, trasmisibles según un esquema de transferencias que tendía a garantizar su permanencia en la órbita familiar. En tal sentido la importancia del patrono era muy grande, pues funcionaba como una especie de fundador de segunda instancia al tiempo que su condición de cónyuge, hijo/a o sobrino/a del fundador reforzaba su íntima relación con todos los componentes, materiales y humanos, de la obra.

Algunas características típicas del perfil testamentario del Antiguo Régimen se reproducían en estas fundaciones piadosas: importancia de los esposos como garantes del cumplimiento de la voluntad del fallecido, primacía de la descendencia adulta y masculina -con los primeros hijos varones como beneficiarios principales-, jerarquización de la vía pacífica para laudar conflictos sancionando los reclamos indebidos. ${ }^{66}$

Hijos, nietos y eventualmente sobrinos en plan de seguir la carrera eclesiástica eran los más favorecidos por estas particulares combinaciones de materia y espíritu. Conforme las familias fueron creciendo en más de una dirección y se presentaron situaciones personales diferentes la estructura de ese micromundo social se tornó más compleja y el propio funcionamiento de cada obra reflejó en cierta medida los movimientos humanos.

Dos fundaciones individuales: una, la de Domingo, casado y con numerosos hijos, y otra, la de Salvador, soltero y deseoso de proporcionar recursos a sus parientes por vía materna, pusieron en marcha mecanismos de transmisión que en poco tiempo involucraron de diferentes maneras a miembros de dos familias, los Bauzá y los García. La capellanía vino a funcionar pues como un articulador de vínculos, unas veces conflictivos y otras no, entre dichos agrupamientos.

Las inversiones montevideanas fueron relativamente pequeñas. En ningún caso movilizaron capitales siquiera aproximados a los de otras zonas del impe-

66 GARCÍA FERnÁndeZ, Herencia y patrimonio..., ob. cit., pp. 195-196. Sobre herencias y conflictos familiares, es más que interesante el aporte de Anastasio AlEMÁn ILlán, Actitudes colectivas ante la muerte en Murcia durante el siglo XVIII, Murcia, Universidad de Murcia, 1992, pp. 173-178, disponible en versión electrónica: www.cervantesvirtual.com/FichaObra.html?Ref=4593 
rio hispánico ${ }^{67}$ Esto, sumado al hecho de que el monto previsto por el fundador y el efectivamente disponible al escriturarse la capellanía no siempre coincidían, armoniza con las reducidas dimensiones que en los planos económico y socio-demográfico exhibía Montevideo en el contexto de las ciudades coloniales, hecho que sin dudas tuvo consecuencias en la vida familiar.

El tenor del litigio entre Petrona Tristán y Guillermo Bauzá aporta datos sobre los procesos de secularización en curso desde finales del siglo XVIII. En los días del reformismo borbónico se incrementaron las presiones sobre muchos de los privilegios eclesiásticos, en especial los económicos, y el fuero civil fue ganando desde entonces más terreno en los tribunales. ${ }^{68}$ En el debate sostenido a comienzos de 1830 se perciben las tensiones existentes entre la declinante tradición del derecho canónico y la ascendente del civil. En la primera mitad del siglo XIX el régimen de cristiandad se mantenía, pero empezaba a perder su carácter monolítico.

${ }^{67}$ WOBESER, «La función social y económica...», ob. cit., pp. 125-126. Según esta autora, en México varias capellanías contaron con un capital fundacional que ascendió a cifras de 60.000 y hasta 200.000 pesos.

68 Manuel Teruel Gregorio de Tejada, Vocabulario básico de la historia de la Iglesia, Barcelona, Crítica, 1993, pp. 64-65. El proceso de crítica y desamortización que afectó al sistema capellánico en Buenos Aires, desde los años finales del período colonial a las primeras décadas del siglo XIX es bien estudiado por Abelardo LeVAGGi, Las capellanías en la Argentina. Estudio históricojurídico, Buenos Aires, Facultad de Derecho y Ciencias Sociales - Universidad de Buenos Aires, 1992, pp. 137-155.

Hispania Sacra, LXIII

127, enero-junio 2011, 261-282, ISSN: 0018-215-X 


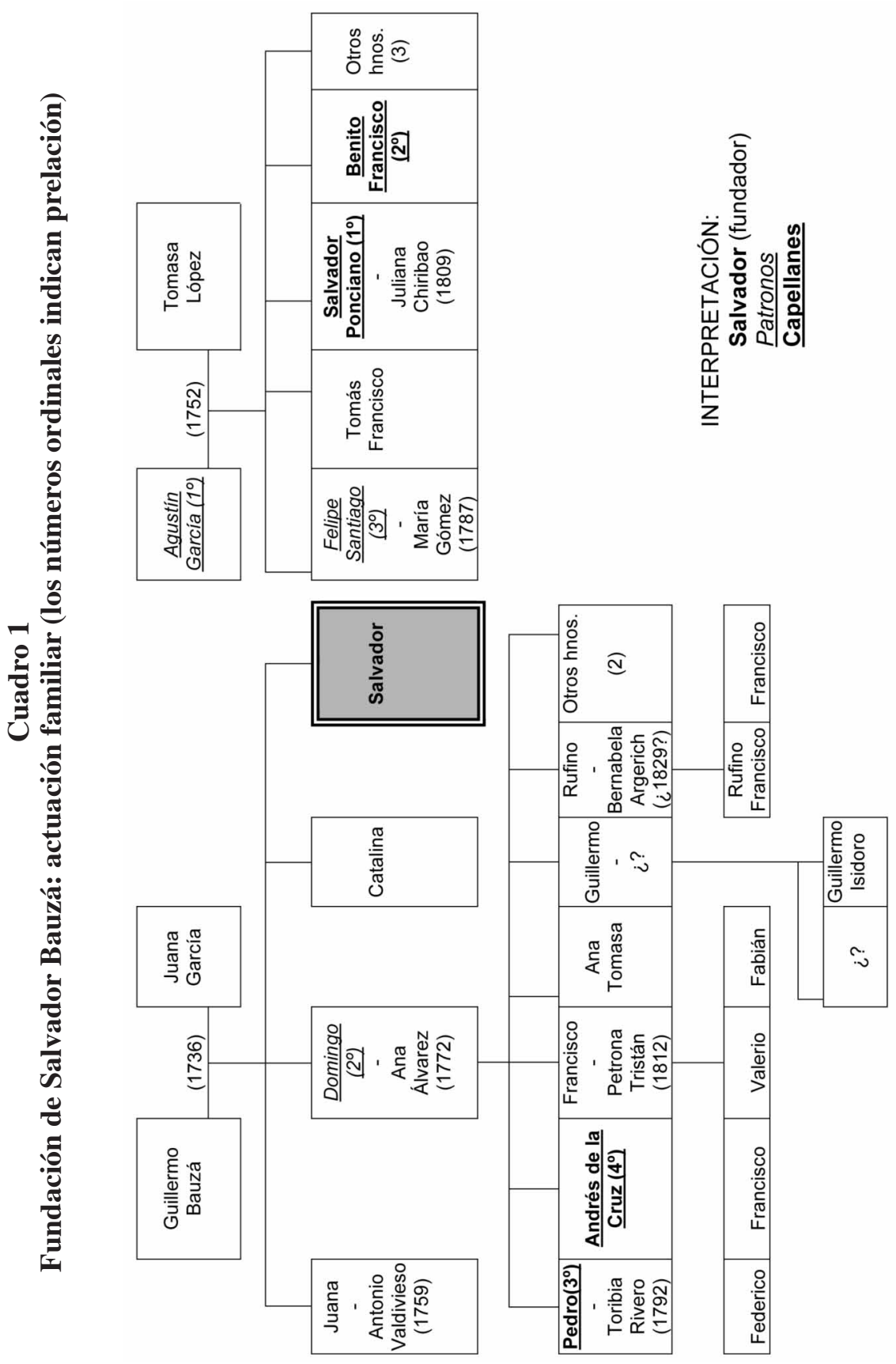

Hispania Sacra, LXIII 127, enero-junio 2011, 261-282, ISSN: 0018-215-X 


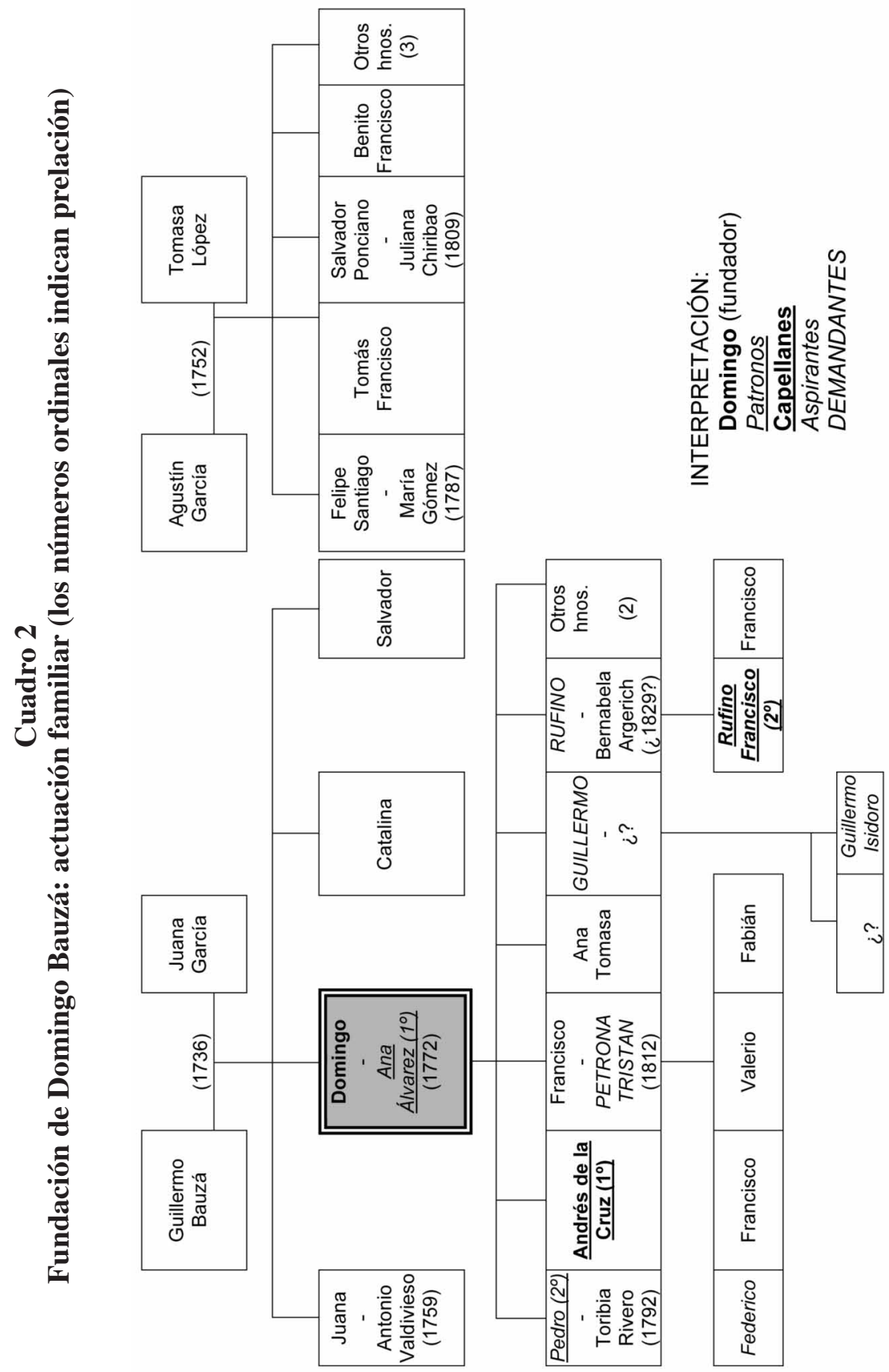

Hispania Sacra, LXIII

127, enero-junio 2011, 261-282, ISSN: 0018-215-X 